\title{
Intelligent Prediction of Clinker Formation Condition for Steam Boiler Tubes Using Artificial Neural Network
}

\author{
Firas Basim Ismail ${ }^{1,}$, Yeo Kee Wei ${ }^{1}$, and Noor Fazreen Ahmad Fuzi ${ }^{1}$ \\ ${ }^{1}$ Institute of Power Generation, Faculty of Mechanical Engineering, Universiti Tenaga Nasional, Jalan IKRAM-Uniten, 43000 \\ Kajang, Selangor Darul Ehsan, Malaysia
}

\begin{abstract}
Ash, as one of the by-product of combustion either accumulates onto boiler tubes as slag or is collected by electrostatic precipitators attached to the backend of the boiler. Flue gas will transport these ash particles either to the inner surfaces of the boiler or to the dust collecting facilities at the backend of the boiler. Sintered ash deposits formed in the radiant section of the boiler are known as clinkers and they contribute to a wide variety of problems to the boiler. Preventative measures to combat clinker formation is in dire need to the energy sector. In this study, a prediction model using real plan data was developed for detection of clinker formation conditions. Several variations of Artificial Neural Networks were tried and test, with emphasis given on the feed-forward neural network, cascade neural network and recurrent neural network. In addition, sensitivity analysis was also conducted to determine the influence of random input variables to their respective response variables. The Tornado Diagram is selected as the method to determine the most influential parameter for clinker formation. It is expected that the Recurrent Neural Network prediction model and the identified most influential input parameter for clinker formation will assist operators in decision making for the maintenance of boilers.
\end{abstract}

\section{Introduction}

The discovery of electricity is one of the greatest achievements of man, thus existence of power plants for the generation of electric power from resources such as coal and gas is of utmost importance as it has become a part of modern life. Pulverised coal combustion is known to be the mostly widely used technology for producing electricity across the world over the last several decades. The most efficient power plants can be operational for longer periods and thus improve financial performance. In that respect, the efficient operation of the furnace is of significant interest in today's competitive power generation industry.

Operational problems occur as a result of high inorganic constituents that are present in coals [1]. Coal is known to be a mixture of combustible solid hydrocarbon and incombustible mineral matter. When pulverised coal is combusted, the mineral matter in the coal transforms into ash during combustion. These ash particles are then entrained in the flue gas flow along the furnace domain and impact on the furnace wall surfaces during their passage through the boiler. The amount and type of inorganic constituents play a major role in the design, maintenance and availability of coal-fired plants. In particular, for low-rank coals, high levels of sodium are mainly responsible for the fouling in combustion chambers [2]. The ash deposition problem is dependent on fuel composition, boiler design and operating conditions [3].

The development of artificial neural network (ANN) in recent years has established growing interest in applying this approach to the area of power system and generation [4]. Modelling a power plant proves to be a challenging issue. Regardless, real data are constantly captured and stored in the database of an operating power plant. These already stored data can be utilised for the development ANN models for predicting clinker formation conditions on steam boiler tubes.

In this study, the step-by-step development of ANN model for the operation of a coal-fired power plant in Malaysia is reported. Three types of ANN models were trained with real plant data. Specifically, these types of ANN models are the Feed-Forward Neural Network (FFNN), Cascade Neural Network (CNN) and the Recurrent Neural Network (RNN). The outcome of the actual output to the predicted output was discussed briefly. A sensitivity analysis was conducted using the tornado diagram to study the relative importance of the input parameters to the output parameters at the end of the study. A prediction model that is capable of predicting the clinker formation conditions can promote the reduction in cost for unplanned maintenances due to problems such as boiler tube corrosion, localised overheating, and ash hopper explosion.

\footnotetext{
* Corresponding author: Firas@uniten.edu.my
} 


\section{Brief Review on Past Works}

A few works has been surveyed to obtain a general idea on how to develop the prediction of clinker formation conditions model. Satish Kumar et. al. conducted a survey on Artificial Intelligence (AI) to overcome problem in power plant such as complication in technical advancement [5]. Arun Kumar et. al. and Samuel A. Oluwadore et. al. studied on implementation of AI in power plant and proved that AI was better than conventional technique when it comes to a large amount of data information $[6,7]$.

E. Teruel et al. conducted a study on the monitoring and prediction of fouling in coal-fired boilers using ANN [8]. J. Purbolaksono et al. examined the causes on a primary superheater tube of a power plant. M.M. Rahman et al. investigated the root cause for the failure of a division wall superheater tube of a coal-fired power station. J. Ahmad et al. discovered the causes of localised overheating of a primary superheater tube on high operating steam [9-11].

B. Pena et al. suggested a probabilistic model to predict the effectiveness of soot-blowing using ANN and Adaptive Nuero-Fuzzy Inference Systems (ANFIS) [12]. H.B. Vuthaluru et al. identified regions that were prone to clinker formations using Computational Fluid Dynamics (CFD) [13]. J.M. Lee et al. studied the effect of cocombustion of anthracite with different grades of coal on the performance of the Circulating Fluidised Bed (CFB) boiler [14]. S. Goyal and G.K. Goyal compared the CNN and FFNN models on the prediction of sensory quality of instant coffee flavoured sterilised drink [15]. A. Sriram et. $a l$. and T.E. Boukelia adopted ANN to power plant to study and evaluate the power plant to achieve the total of capacity, reduce operation cost and increase the annual performance of each plant $[16,17]$.

S.A. El-Temtamy and T.S. Gendy studied the economic evaluation and sensitivity analysis of some fuel oil upgrading processes, including the tornado diagram method [18]. H.B. Vuthaluru and D.H. French investigated clinker formation and the variation on deposit characteristics with time in a large-scale pulverised coal boiler [19]. A. Arjunwadkar et al. reviewed some of the operation and maintenances issues of CFB boilers [20]. Recently, Victor Henrique Cobral Pinheiro et. al. identifying problems in nuclear power plant by using AI specifically GA method [21].

\section{The Technical Problem}

Strong bonded deposits called clinkers are formed when ash deposit fuses to the furnace walls and tubes of a boiler. Due to strong bonding with the furnace walls, traditional sootblower implemented for the removal of ash deposits are ineffective for the removal of clinkers. In much serious cases, when the deposits detach and fall down from the walls, they might damage boiler tubes thus resulting in power disruption or outages of power plant.

\section{Method}

\subsection{Basic ANN}

Artificial Neural Network (ANN) can be described as a mathematical mapping of an input space to an output space [22]. ANN builds it neural architecture by adapting to experience; an ANN model consist of several interconnected artificial neurons that process information in parallel.

The ANN model learns pattern recognition by teaching it to recognise sets of input-output pattern pairs in such a way that when a testing pattern is presented to the model, it is able to recall the corresponding stored input-output pattern [23]. The main advantage of using ANN is that it does not need any mathematical model, since it learns from historical data to recognise nonevident relations and patterns in a set of input-output variables, without any prior assumption about their nature.

In this study, three types of ANN were used to determine the best model to predict clinker formation conditions, which are the FFNN, CNN and RNN. The FFNN consist of an input layer, one or more hidden layers, and an output layer. Generally, the inputs to the network would be multiplied by its adjustable weight, summed and transferred in the neurons to produce an output.

The CNN and RNN are permutations to the basic feed-forward neural network. In the $\mathrm{CNN}$, each subsequent layer has weights coming from the input from all previous layers. Simply put, the flow of information is unidirectional except that there is an extra weight connection from the input to each layer [24]. In the RNN, it consist of at least one feedback connection, so the activations can flow round in a loop. In other words, it allows feedback connection from either the output later or hidden layer to the input layer.

\subsection{Development of ANN Model}

\subsubsection{Data Pre-Processing}

Data collection is the first step to develop the prediction model for clinker formation conditions. Data for a large number of parameters are usually collected in a power plant. All necessary data was obtained from the plant information station of the power plant in Malaysia. The data collected for 86 sets of parameters spans for a duration of three month at a time interval of 10 minutes. Additionally, the data collected may have missing or inaccurate value since the real data collected contains thousands of value. Thus, the raw data need to be visually inspected for any invalid data and readjusted or removed before setting up for normalisation. After data treatment, data reduction was initiated to narrow down to the scope and relevancy of the study. The data was reduced to 39 sets of parameter, which after further reduction by averaging similar parameters, narrowed down the parameters to 7 input and 3 target parameter. 


\subsubsection{Selection of Training Data}

The selected input parameters for this study is tabulated in Table 1 below.

Table. 1. Selected input parameters for ANN modelling

\begin{tabular}{|c|c|c|}
\hline No. & Input Data & Unit \\
\hline 1 & $\begin{array}{c}\text { Mean air/pulverised fuel(PF) mill } \\
\text { strength }\end{array}$ & - \\
\hline 2 & RH total secondary flow & $\mathrm{kNm}^{3} / \mathrm{hr}$ \\
\hline 3 & LH total secondary flow & $\mathrm{kNm}^{3} / \mathrm{hr}$ \\
\hline 4 & Mean burner tilt position & $\%$ \\
\hline 5 & $\begin{array}{c}\text { Mean feeder coal flow } \\
\text { temperature }\end{array}$ & $\mathrm{Ton} / \mathrm{hr}$ \\
\hline 7 & $\begin{array}{c}\text { Mean economiser outlet } \\
\text { Economiser inlet temperature }\end{array}$ \\
\hline
\end{tabular}

The selected target parameters for this study is tabulated in Table 2 below.

Table. 2. Selected target parameters for ANN modelling

\begin{tabular}{|c|c|c|c|}
\hline No & Targets & Unit & $\begin{array}{c}\text { Condition } \\
\text { Requirements }\end{array}$ \\
\hline 1 & $\begin{array}{c}\text { Mean flue gas outlet } \\
\text { temperature }\end{array}$ & ${ }^{\circ} \mathrm{C}$ & $\begin{array}{c}\text { If above } 160^{\circ} \mathrm{c} \text {, target } \\
\text { data equals } 1 . \text { Else, } \\
\text { target data equals to } 0 .\end{array}$ \\
\hline 2 & $\begin{array}{c}\text { Change in } \\
\text { temperature for mean } \\
\text { final superheater } \\
\text { outlet temperature }\end{array}$ & $\%$ & $\begin{array}{c}\text { If above } 5 \% \text { in change, } \\
\text { target data equals } 1 . \\
\text { Else, target data equals } \\
\text { to } 0 .\end{array}$ \\
\hline $\begin{array}{c}\text { Change in } \\
\text { temperature for mean } \\
\text { high temperature } \\
\text { (HT) reheater outlet } \\
\text { temperature }\end{array}$ & $\%$ & $\begin{array}{c}\text { If above } 5 \% \text { in change, } \\
\text { target data equals } 1 . \\
\text { Else, target data equals } \\
\text { to } 0 .\end{array}$ \\
\hline
\end{tabular}

The input parameters selected was based on the advice of power plant experts. The selection was mainly because it is the input conditions for the boiler. Large changes to these value can directly affect the plant load conditions and flue gas exit temperature. For the inlet and outlet economiser temperature, they were selected because it acts as a last resort heat capturing device to preheat the water below the drum saturation temperature. Since the remaining heat energy is transferred into the economiser, the flue gas exit temperature should decrease.

Targets in ANN modelling refers to the desired outcome or results of the ANN model. For this study, three targets has been chosen for the raw data collected from the plant information station. To justify the first target, the formation of clinker is largely due to the flue gas temperature at the convective components of the boiler exceeding the ash fusion temperature of the coal. This will cause sintering in the ash deposits in the boiler layout. However, the flue gas temperature at each convective component is unavailable. The only available data from the data provided is the outlet flue gas flow temperature. From literature, it was suggested that for boiler units with a capacity of above $10 \mathrm{ton} / \mathrm{hr}$, the temperature of the exit flue gas is taken equal to 120-180 ${ }^{\circ} \mathrm{C}[25]$. Assuming that when the mean outlet flue gas flow temperature is above $160^{\circ} \mathrm{C}$, the target data was set to 1 , suggesting that the heat flux capabilities of the convective components is hindered by the formation of slag and clinkers on the surface and when it is below $160^{\circ} \mathrm{C}$, the target data was set to 0 , suggesting that the convective components is capable of normal heat flux capabilities and it is free from slag and clinker formation.

For the second and third target, assuming that the change in temperature for the second and third targets are above $5 \%$, the target data will set to 1 . In the case of the change in temperature is below $5 \%$, then the target data will be set to 0 . The reasoning is similar to the first target. When the change of temperature is larger than $5 \%$ of the maximum temperature of the boiler tubes, then it is likely that the heat transfer process is hindered by the formation of clinkers of the surface of the boiler tubes.

\subsubsection{ANN Structure and Training}

The feed-forward, cascade and recurrent ANN model was used for this study. For the purpose of identifying the best ANN model to predict clinker formation conditions, the trial and error method was employed to obtain the lowest Root-Mean Square Error (RMSE). The RMSE represents the error value of the output value of the ANN model to the actual output value of the real data during the network training period. RMSE is usually related to the performance of the ANN model. The lower the RMSE value, the better the performance of the model.

Four types of transfer function was selected to be tried and tested, which are the levenberg-marquardt (trainlm), resilient backpropagation (trainrp), BFGSQuasi Newton (trainbfg) and scaled conjugate gradient (trainscg). In this study, the 1 hidden layer (1HL) and 2 hidden layer (2HL) will be tried for each ANN configuration. The training sets is divided to $40 \%$ for training, 30\% for validation and $30 \%$ for testing. The activation functions used are the log-sigmoid (L), tansigmoid (T) and purelin (P). The combinations of activations, for example the 1HL ANN models, with L+T means that the ANN model uses a combination of Logsigmoid and Tan-Sigmoid. For the 1HL ANN models, the maximum possible combination is 9 while the $2 \mathrm{HL}$ ANN models is 27 . MATLAB 2014b software was used to simulate ANN modelling.

\subsubsection{Sensitivity Analysis}

A sensitivity analysis can be defined as the study of how uncertainty in the output of the model can be apportioned to different sources of uncertainty in the model input [26]. A sensitivity analysis is usually carried out as soon as model coding is completed. It offers two benefits; the first is to act as a check on the model's logic and the robustness of the simulation, and the second is to define the importance of model parameters and thus the effort in which must be invest in data acquisition for different 
parameters. In this study, the tornado diagram method was employed to perform a simple sensitivity analysis.

A tornado diagram is a horizontal bar chart, where each bar represents one variable, and the length of each bar represents the change in consequence; the longer the bar, the higher its sensitivity to the output is. In a tornado analysis, each parameter is perturbed while all the others are kept at their mean (best estimate) values. Two values, specifically an upper and lower bound, are used to simulate such variation. The tornado diagram offers mainly two advantages [27]. The first is that the graph is particularly useful if there is a large number of uncertain inputs in the valuation model and it is impractical to analyze them all carefully. Secondly, it allows the detection of asymmetries and therefore potential flaws in averages.

To employ the tornado diagram, a relationship between all the input parameters to the specified output parameter is needed. For this reason, the multiple linear regression method is utilised to model the relationship between the input parameters to the response parameters.

\section{Result}

\subsection{Best RMSE ANN Model}

The trial-and error method to determine the best RMSE ANN model was performed, and table 3 below is the summary for the best RMSE ANN model for each catagory.

Based on table 3 below, the $2 \mathrm{HL}$ RNN model has the lowest RMSE value among 6 different types of ANN models, although there is little differences in RMSE value between each model.

In the previous section, the best RMSE ANN model has been identified, but it is insufficient to justify it as the absolute best ANN model for this study. An investigation on the actual and predicted output is essential to justify and support the best ANN model for clinker formation conditions. As mentioned previously, this study has three output parameters, which are the final superheater outlet temperature, HT reheater outlet temperature and mean outlet flue gas temperature. 'Critical points' in the graphs are highlighted, which is defined as the point anywhere in the graph that has a normalised value of closest to one and/or the point in which the predicted output is able to predict the actual pattern beforehand.

\subsection{Outcome Analysis}

Figure 1 below shows the outcome analysis graph for the $1 \mathrm{HL} \mathrm{CNN}$ for the change in final superheater outlet temperature, accompanied by table 4 for the comparison of critical points for the change in final superheater temperature.

Figure 2 below shows the outcome analysis graph for the 2HL RNN for the change in HT reheater outlet temperature, accompanied by table 5 for the comparison of critical points for the change in HT reheater outlet temperature.
Table. 3. Summary of best RMSE ANN models for each category

\begin{tabular}{|c|c|c|c|c|c|}
\hline $\begin{array}{c}\text { Type of } \\
\text { ANN }\end{array}$ & $\begin{array}{c}\text { Transfer } \\
\text { function }\end{array}$ & $\begin{array}{c}\text { 1HL } \\
\text { neuro } \\
\text { ns }\end{array}$ & $\begin{array}{c}\text { 2HL } \\
\text { neuro } \\
\text { ns }\end{array}$ & $\begin{array}{c}\text { Activation } \\
\text { function }\end{array}$ & $\begin{array}{c}\text { RMSE } \\
\text { value }\end{array}$ \\
\hline $\begin{array}{c}\text { 1HL } \\
\text { FFNN }\end{array}$ & Trainlm & 5 & - & L+T & 0.2625 \\
\hline $\begin{array}{c}\text { 1HL } \\
\text { CNN }\end{array}$ & Trainlm & 5 & - & L+T & 0.2652 \\
\hline $\begin{array}{c}\text { 1HL } \\
\text { RNN }\end{array}$ & Trainlm & 9 & - & L+T & 0.2641 \\
\hline $\begin{array}{c}\text { 2HL } \\
\text { FFNN }\end{array}$ & Trainlm & 5 & 7 & T+T+T & 0.2607 \\
\hline $\begin{array}{c}\text { 2HL } \\
\text { CNN }\end{array}$ & Trainrp & 2 & 5 & P+P+T & 0.2624 \\
\hline $\begin{array}{c}\text { 2HL } \\
\text { RNN }\end{array}$ & Trainlm & 4 & 4 & P+T+T & $\mathbf{0 . 2 5 8 8}$ \\
\hline
\end{tabular}

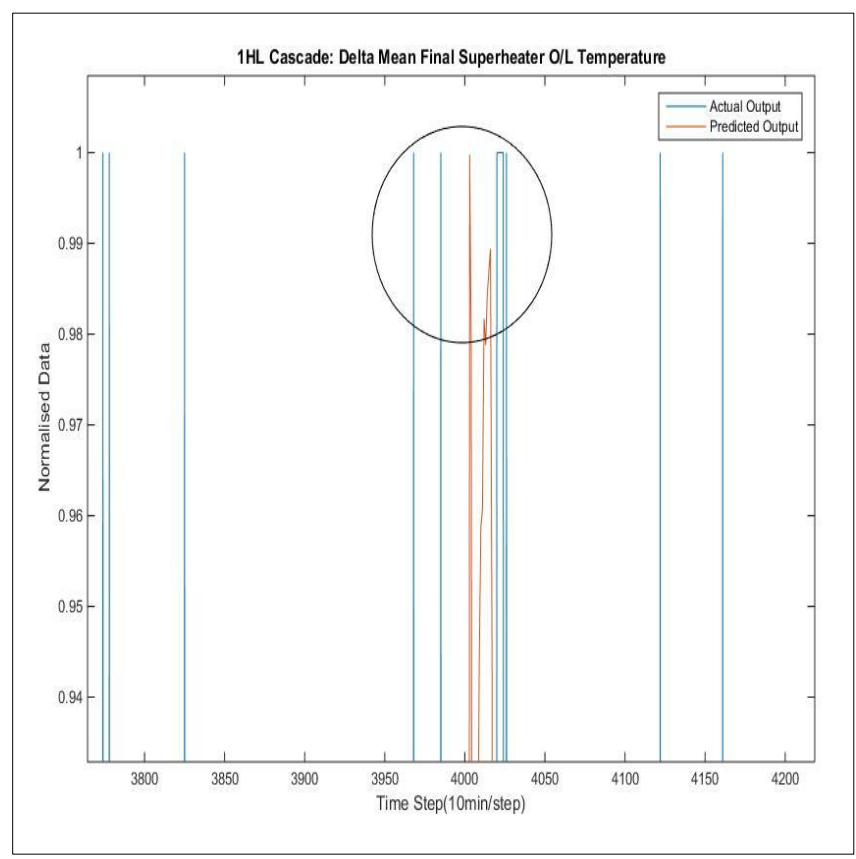

Fig. 1: Critical point for 1HL CNN final superheater outlet temperature

Figure 3 below shows the outcome analysis graph for the $2 \mathrm{HL}$ RNN for the change in mean flue gas outlet temperature, accompanied by table 6 for the comparison of critical points for the change in mean flue gas outlet temperature.

Table 7 below shows the summary for the best ANN model for each category of the outcome analysis and the best RMSE ANN model. 
Table. 4. Comparison of critical points for final superheater outlet temperature

\begin{tabular}{|c|c|c|}
\hline Type of ANN & $\begin{array}{c}\text { Time interval } \\
\text { (10min/interval) }\end{array}$ & Normalised Value \\
\hline 1HL CNN & 4000 to 4030 & $\mathbf{0 . 9 8}$ to 1 \\
\hline 1HL FFNN & 4003 & 0.427 \\
\hline 1HL RNN & 4573 & 0.832 \\
\hline 2HL CNN & 6232 & 0.943 \\
\hline 2HL FFNN & 4573 & 0.774 \\
\hline 2HL RNN & 4573 & 0.683 \\
\hline
\end{tabular}

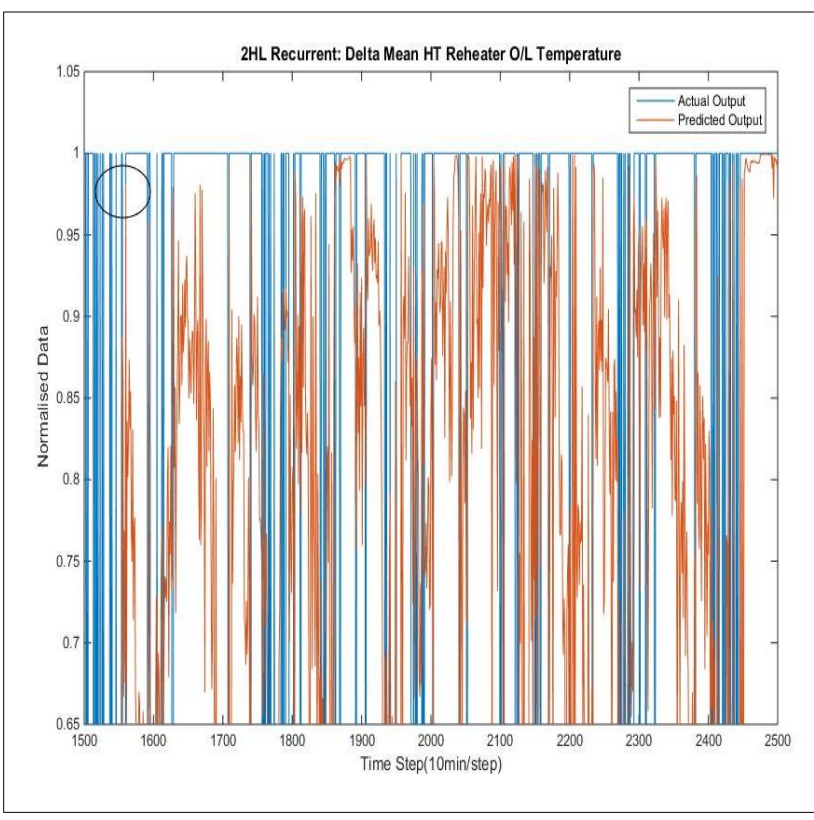

Fig. 2: Critical point for 2HL RNN HT reheater outlet temperature

Table. 5. Comparison of critical points for HT reheater outlet temperature

\begin{tabular}{|c|c|c|}
\hline Type of ANN & $\begin{array}{c}\text { Time interval } \\
\text { (10min/interval) }\end{array}$ & $\begin{array}{c}\text { Normalised } \\
\text { Value }\end{array}$ \\
\hline 1HL CNN & 1555 & 0.968 \\
\hline 1HL FFNN & 1560 & 0.929 \\
\hline 1HL RNN & 1555 & 0.962 \\
\hline 2HL CNN & 1560 & 0.910 \\
\hline 2HL FFNN & 1555 & 0.964 \\
\hline 2HL RNN & 1560 & $\mathbf{0 . 9 8 1}$ \\
\hline
\end{tabular}

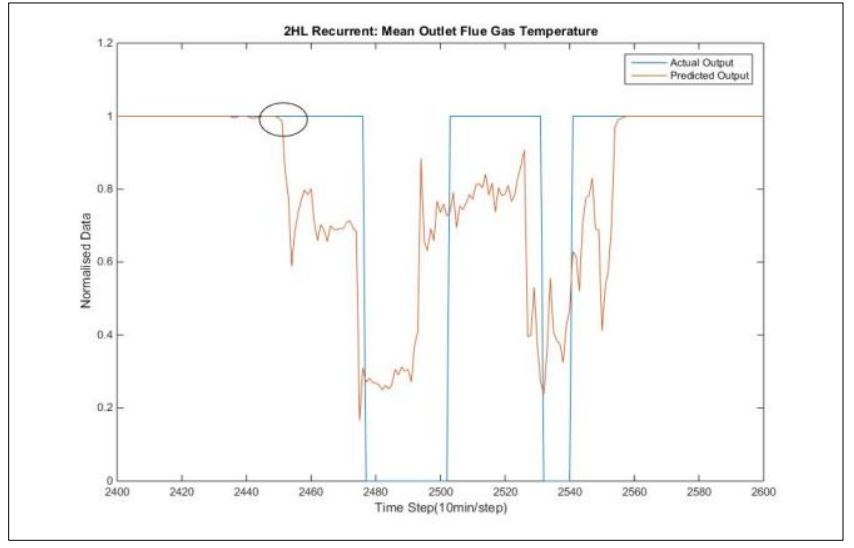

Fig. 3: Critical point for $2 \mathrm{HL}$ RNN mean flue gas outlet temperature

Table. 6. Comparison of critical points for mean flue gas outlet temperature

\begin{tabular}{|c|c|c|}
\hline Type of ANN & $\begin{array}{c}\text { Time interval } \\
(\mathbf{1 0 m i n} / \text { interval) }\end{array}$ & Normalised Value \\
\hline 1HL CNN & 2450 & 0.966 \\
\hline 1HL FFNN & 2451 & 0.908 \\
\hline 1HL RNN & 2451 & 0.656 \\
\hline 2HL CNN & 2453 & 0.614 \\
\hline 2HL FFNN & 2452 & 0.751 \\
\hline 2HL RNN & 2451 & $\mathbf{0 . 5 8 8}$ \\
\hline
\end{tabular}

Table. 7. Summary of best ANN model for each category

\begin{tabular}{|c|c|}
\hline Outcomes & $\begin{array}{c}\text { Type of ANN } \\
\text { models }\end{array}$ \\
\hline Best RMSE ANN model & 2HL RNN \\
\hline $\begin{array}{c}\text { Delta mean final superheater outlet } \\
\text { temperature }\end{array}$ & $1 \mathrm{HL} \mathrm{CNN}$ \\
\hline $\begin{array}{c}\text { Delta mean HT reheater outlet } \\
\text { temperature }\end{array}$ & 2HL RNN \\
\hline Mean outlet flue gas temperature & 2HL RNN \\
\hline
\end{tabular}

\subsection{Tornado Diagram}

Before employing the tornado diagram analysis, the multiple linear regression method to determine the relationship between the input and output is needed. The multiple linear regression method works by fitting a linear equation to the observed data. In this study, Microsoft Excel 2007 version was utilised to calculate the multiple linear regression coefficients. Generally, the model for multiple linear regression, with respect to $\mathrm{n}$ observations is:

$$
y_{i}=\beta_{0}+\beta_{1} X_{i 1}+\beta_{2} X_{i 2}+\ldots \beta_{p} X_{i p}, \text { for } i=1,2,3 \ldots n
$$


Performing the multiple linear regression using the Microsoft Excel software has brought upon 3 equations to represent the input to output of an ANN model. The equations are:

$$
\begin{aligned}
& O_{1}=-11.5369-0.2763 X_{1}+0.0051 X_{2}+0.0144 X_{3} \\
& +0.2167 X_{4}-0.0124 X_{5}+0.5856 X_{6}-0.350 X_{7} \\
& O_{2}=-1.1265-0.0022 X_{1}+0.0001 X_{2}-0.0004 X_{3} \\
& +0.065 X_{4}+0.0051 X_{5}+0.0002 X_{6}+0.005 X_{7} \\
& O_{3}=-28.7092-0.042 X_{1}-0.0022 X_{2}+0.0041 X_{3}+ \\
& 0.2803 X_{4}+0.0909 X_{5}-0.1723 X_{6}-0.0721 X_{7}
\end{aligned}
$$

Where the variables for each inputs and outputs are defined in table 8 .

Table. 8. Variables for multiple linear regression

\begin{tabular}{|c|c|}
\hline Variables & Meaning \\
\hline $\mathrm{X}_{1}$ & Mean air/PF mill strength \\
\hline $\mathrm{X}_{2}$ & RH total secondary air flow \\
\hline $\mathrm{X}_{3}$ & LH total secondary air flow \\
\hline $\mathrm{X}_{4}$ & Mean burner tilt position \\
\hline $\mathrm{X}_{5}$ & Economiser inlet temperature \\
\hline $\mathrm{X}_{6}$ & Mean economiser outlet temperature \\
\hline $\mathrm{X}_{7}$ & Mean feeder coal flow \\
\hline $\mathrm{O}_{1}$ & Mean flue gas temperature \\
\hline $\mathrm{O}_{2}$ & $\begin{array}{r}\text { Delta mean final superheater outlet } \\
\text { temperature }\end{array}$ \\
\hline $\mathrm{O}_{3}$ & $\begin{array}{r}\text { Delta mean HT reheater outlet } \\
\text { temperature }\end{array}$ \\
\hline
\end{tabular}

The results comparisons of the multiple linear regression is available in table 9. The values between the actual mean value of the output is close to the estimated output value. Hence, it can be said that the multiple linear regression equations are able to represent the ANN model closely.

Table. 9. Comparison of actual and estimated mean value

\begin{tabular}{|c|c|c|c|}
\hline $\begin{array}{c}\text { Mean } \\
\text { Value }\end{array}$ & $\begin{array}{c}\text { Mean flue } \\
\text { gas } \\
\text { temperature } \\
\left({ }^{\circ} \mathrm{C}\right)\end{array}$ & $\begin{array}{c}\text { Delta mean } \\
\text { final } \\
\text { superheater } \\
\text { outlet } \\
\text { temperature } \\
(\%)\end{array}$ & $\begin{array}{c}\text { Delta mean } \\
\text { HT reheater } \\
\text { outlet } \\
\text { temperature } \\
(\%)\end{array}$ \\
\hline Actual & 170.66 & 2.20 & 4.80 \\
\hline Estimated & 170.68 & 2.32 & 4.77 \\
\hline
\end{tabular}

Figure 4 shows the tornado diagram for the change in final superheater outlet temperature.
Figure 5 shows the tornado diagram for the change in HT reheater outlet temperature.

The tornado diagram for three target parameters are presented, which is the change in final superheater outlet temperature, change in HT reheater outlet temperature and change in mean flue gas outlet temperature. It is important to understand the relative importance of the input parameters to the target parameters as it allows control and maintenance for the particular model. The input parameters are ranked for the most influential to the least influential based on the position on the tornado diagram; the top position is regarded as the most influential input parameter and the bottom position is the least influential input parameter.

\section{Delta Mean Final Superheater O/L Temperature} (\%)

$0.150 .100 .050 .00-0.05-0.10-0.15$

Mean Burner Tilt Position

Economiser Inlet...

Mean Economiser Outlet..

LH Total Secondary Flow

Mean RC Coal Flow

RH Total Secondary Flow

Mean Air/PF Mill Strength

Fig. 4: Tornado diagram for the change in final superheater outlet temperature

Delta Mean HT Reheater O/L Temperature (\%) $-3.00-2.00-1.000 .001 .002 .003 .00$

\section{Mean Economiser Outlet... \\ Economiser Inlet... \\ Mean Burner Tilt Position \\ Mean RC Coal Flow \\ LH Total Secondary Flow \\ RH Total Secondary Flow \\ Mean Air/PF Mill Strength}

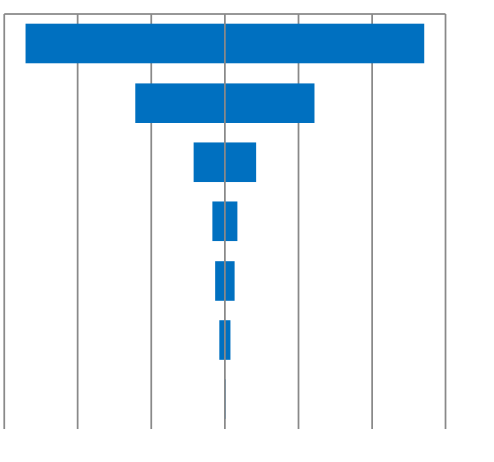

Fig. 5: Tornado diagram for the change in HT reheater outlet temperature

Figure 6 shows the tornado diagram for the change in mean flue gas outlet temperature. 


\section{Mean Outlet Flue Gas Temperature $\left({ }^{\circ} \mathrm{C}\right)$} $-15.0010 .005 .000 .005 .0010 .005 .00$

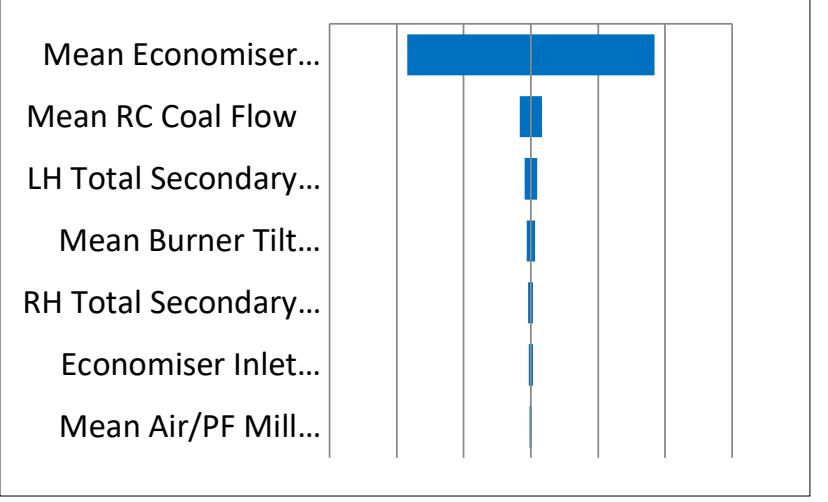

Fig. 6: Tornado diagram for the change in mean flue gas outlet temperature

\section{Discussions}

\subsection{Outcome Analysis}

As seen in table 4, It is observable that the 1HL Cascade is the only ANN model that is capable of detecting a change in the mean final superheater outlet temperature within a range. In this aspect, it is highly favorable that the 1HL CNN should be utilised to represent the boiler modelling for the change in final superheater outlet temperature. Observing the actual output pattern show that power plant station's final superheater outlet temperature is constantly fluctuating, which may be a large indication of high velocity, turbulent behavior for the flue gas bombarding the final superheater tubes, causing ineffective heat transfer due to low residence time or clinker formation on the tubes hindering the heat transfer process. The predicted output for all models shows large fluctuation at approximately 2000 to 5000 time interval.

The superheater is considered as one of the most important accessories in a boiler, alongside the reheater, that improves the thermal efficiency of the boiler. A superheater functions to remove the last traces of moisture from saturated steam to superheated steam before entering into the turbine to generate electricity. Due to the combustion of coal that produces ash, the formation of clinker propensities on the surface of superheater will occur if proper precautionary steps are not taken. Slag and clinker formations are also the main reason why sootblowers are used in pulverised coal boilers. After ash particles deposit builds up on the superheater tube surface, the thermal conductivity of the superheater tubes reduces while it's thermal resistance becomes greater. This causes a decrease in the absorption of heat.

Large deviation from the maximum temperature suggests that the slag deposit on the boiler tubes have grown considerably thick, and probable clinker formation might occur. Prolonged clinker formation of superheater tubes maybe cause tube corrosion and localised heating. When the final superheater outlet temperature decreases, it may hinder the process of raising the steam temperature from saturation conditions to the desired final temperature. Water droplets may form and this may cause erosion and corrosion damage to the turbine blades. This shows how severe clinker formation may affect the boiler's overall performance and also stresses the importance of monitoring clinker formation inside the boiler.

Hence the superheater bank, which usually consists of relatively closely spaced small tubes, must be kept clean. The velocity and temperature of flue gases should be as uniform as possible to the entering area of the superheater for the protection of the tubes. It should be kept uniformly clean, because if certain areas accumulate ash and the flow of flue gas is directed to a limited portions of the superheater, the higher gas-mass flow may quickly overheat such portions of the superheater tubes.

Based on table 5, it is obvious that the HT reheater outlet temperature change occurs at about 1555 or 1560 time interval. Each and every ANN model is able to predict this time with fairly accurate normalised value close to 1 . In this aspect, it can be considered that all ANN models are able to accurately portray the change of HT reheater outlet temperature, with high favor to the $2 \mathrm{HL}$ Recurrent architecture as it has the highest normalised value of 0.981 . The $2 \mathrm{HL}$ Recurrent model should be utilised to represent the boiler modelling for the change in mean HT reheater outlet temperature.

Similarly to delta mean final superheater outlet temperature, the actual output indicates that HT reheater undergoes a high velocity, turbulent bombardment of the flue gas to the reheater tubes, causing low residence time and consequently ineffective heat transfer to the steam. Judging by how chaotic the change in HT reheater outlet temperature, it is safe to say that this is caused by a combination of highly turbulent flue gas behavior coupled by clinker formation on the reheater tubes that hindered the heat transfer process. The power plant station has high probability that the reheater tubes are afflicted with severe clinker formation during the period of investigation.

A reheater mainly functions by withdrawing a part of the exhaust gas from the turbine back to the boiler for reheating purposes; the reheat steam is at a much lower pressure when compared to superheated steam. However, the final reheater temperature should be close to or the same as the superheated steam temperatures. Reheating the steam to high temperatures will improve the efficiency of the boiler.

A similar explanation to the final superheater outlet temperature change may be employed for the reheater, as is it located just behind the superheater inside the boiler. Clinker deposition build up will decrease the heat flux capabilities of high temperature reheater tubes. As the clinker deposit grows thicker, the thermal resistance of the reheater tube increases; thus causing a reduction of the reheater outlet temperature. Large deviation from the maximum temperature suggests that the slag deposit on the boiler tubes have grown considerably thick, and probable clinker formation might occur. Prolonged clinker formation of reheater tubes maybe cause tube corrosion and localised heating. 
According to table 6, it is obvious that the mean outlet flue gas temperature drops below $160{ }^{\circ} \mathrm{C}$ at critical point about 2450 or 2453 time interval. All the ANN model is able to predict the drop in temperature ahead of time, albeit at varying normalised value in the range between 0.55 to 0.95 . In this aspect, the ANN models that are able to accurately portray the change of HT reheater outlet temperature are the 1HL Cascade, 1HL Recurrent and 2HL Cascade architecture, with high favor to the $2 \mathrm{HL}$ Recurrent architecture as it has the lowest normalised value of 0.588 . The 2 HL Recurrent model should be utilised to represent the boiler modelling for mean outlet flue gas temperature.

Observations made on the actual output for the mean outlet flue gas temperature for the power plant station indicates that it is constantly above $160{ }^{\circ} \mathrm{C}$ with a few fluctuations below the aforementioned temperature. The few fluctuations that are below $160{ }^{\circ} \mathrm{C}$ has been confirmed to be borderline fluctuation through manual screening of the actual output data. This means that the steam boiler tubes in the furnace is afflicted with clinker formation and cleaning is highly recommended.

The mean outlet flue gas temperature represents the temperature of combustion gases as they exit the boiler. It is important that this temperature is constantly monitored as it represents a major portion of the energy that is not converted to usable output. The higher the mean outlet flue gas temperature signifies lesser energy is transferred through the boiler tubes and consequently a lower boiler efficiency.

Ideally in the boiler, there must be complete combustion of the fuel but practical difficulties makes it difficult to supply the exact amount of air. Hence, excess air must be introduced in the boiler to accommodate complete combustion. Too little air supplied will result in incomplete combustion that produces less heat, Carbon Monoxide (CO), smoke, water droplets and also a higher ash content due to unburnt carbon. On the other hand, too much air supplied is equally undesirable since it cools the boiler and removes useful heat.

It is also possible that combustion can be incomplete even though there is enough, or even excess air supplied to the boiler due to the reasons below [28].

- Air passes through the boiler without proper mixing with the fuel.

- The fuel is not heated enough to react with the air.

- Fuel and air does not have enough time to react before the combustion product are being cooled off.

The mean outlet flue gas temperature is closely related to the change in temperature for the final superheater and HT reheater outlet temperature. When the heat absorption capabilities of the steam boiler tube decreases, then there will be an increase in the mean outlet flue gas temperature. This explains why a higher mean outlet flue gas temperature is a sign that there is probable clinker formation.

\subsection{Tornado Diagram}

In figure 4, the input parameters that rank from most important to least important to the change in mean final superheater outlet temperature is as follows: mean burner tilt position, economiser inlet temperature, $\mathrm{LH}$ total secondary flow, mean $\mathrm{RC}$ coal flow, $\mathrm{RH}$ total secondary flow, mean economiser outlet temperature and mean air/PF mill strength.

The mean burner tilt position influences the change in mean final superheater outlet temperature greatly, according to Figure 2.45. Burner tilt angle are used to control reheat steam temperatures. However, when burner tilt angles are employed, both reheat and superheat temperatures are affected. In a scenario where the boiler operator detects a low reheat temperature, the burner tilt angles will be raised and consequently the furnace fire. This allow more heat into the convective pass to raise the reheat steam temperature. Hence, a higher burner tilt angle will increase the firing rate, the reheat steam temperature will increase alongside the superheat steam temperature at a greater scale than the reheat temperature.

The economiser inlet temperature is the second most influential parameter to the change in final superheater outlet temperature followed by the mean economiser outlet temperature. When the inlet feedwater temperature of the economiser is low, that means the outlet feedwater temperature of the economiser is also lower. This will have adverse effect since the steam in the superheater requires a longer time to absorb the heat from the flue gas before leaving for the turbine. Consequently, the mean final superheater outlet temperature will also decrease because the steam in the economiser is not pre-heated to satisfactory temperature. In regards to that, the power plant station should bring focus on optimising the burner tilt position and economiser inlet/outlet temperature to control clinker formations in final superheater tubes.

As seen in figure 5, the input parameters that rank from most important to least important to the change in mean HT reheater outlet temperature is as follows : mean economiser outlet temperature, economiser inlet temperature, mean burner tilt position, mean RC coal flow, LH total secondary flow, RH total secondary flow, and mean air/PF mill strength.

The mean economiser outlet temperature is the most influential parameter to the change in mean HT reheater outlet temperature, followed by the economiser inlet temperature. Although the economiser does not have direct effect on the reheater outlet temperature, it is still very much capable of influencing the change in reheater outlet temperature due to compounding effect. To explain, a low inlet feedwater temperature for the economiser will result in a low outlet temperature for the feedwater, which is then redirected to the superheater to generate superheated steam. If the feedwater temperature is low, then the superheated steam will also have a lower desirable temperature. Once the superheated steam passes through the turbine and is redirected back to the reheater, then it is expected that the inlet temperature will be lower. Hence, the outlet temperature for the reheater will be lowered.

The mean burner tilt position is one of the method to control reheater temperature. The burners are tilted up or lowered down to allow the flame envelope in the furnace to move up and down, causing a good variation in the amount of radiation heat the reheater receives. A 
higher the burner tilt angle will result in higher firing rate that consequently increase the reheat steam temperature. Similarly to the final superheater outlet temperature, it is highly recommended that the power plant station should prioritise on paying close attention to the economiser inlet/outlet temperature and mean burner tilt position to monitor and control clinker formations on HT reheater tubes.

Based on figure 6 , the input parameters that rank from most important to least important to the change in mean outlet flue gas temperature is as follows: Mean economiser outlet temperature, mean RC coal flow, LH total secondary flow, mean burner tilt position, RH total secondary flow, economiser inlet temperature, and mean air/PF mill strength.

The mean economiser outlet temperature greatly affects the mean flue gas temperature. As the economiser mainly function as a waste heat capturing device, it is usually placed at the back end of the boiler to capture as much heat as possible before the mean outlet flue gas exits the boiler. An increase in the mean economiser outlet temperature would signify that there should be a decrease in the mean outlet flue gas temperature.

The Mean feeder coal flow is the second most influential parameter on the mean flue gas temperature. When the coal flow is increase, it means that there is a larger amount of fuel being input to the furnace. To accommodate a larger fuel being input to the furnace, there must be a balance between air/fuel ratio, in this case, the mean air/PF mill strength which consequently increase the firing rate of the burner increases and finally raising the mean outlet flue gas temperature. The higher the firing rate, the higher the mean outlet flue gas temperature and vice versa.

Surprisingly, the mean air/PF mill strength is also considered as the least influential parameter for the mean outlet flue gas temperature. This may be attributed that for power plant station, the air/PF mill strength is remained constant throughout the entire time the real-time data is recorded. Generally, a constant air/PF ratio is good practice as the air is adjusted to promote excess air to the changes in pulverised coal input. It is common that in power plant boilers that there will be excess air during the fuel mixing process to reduce incomplete combustion. The same reasoning can be applied to the change in mean final superheater outlet temperature and mean HT reheater outlet temperature.

The power station should place much effort on monitoring the economiser outlet temperature as it plays huge influence in the mean outlet flue gas temperature. Some attention should be paid to the mean feeder coal flow as a large amount of coal flow would introduce a higher amount of heat energy, accompanied by higher ash content into the boilers. A higher ash content in the boiler would increase the probability of sticky ash that adheres to steam boiler tubes, leading to clinker formation.

As a result, the main input parameters that should be focused is the mean mean burner tilt position, economiser inlet temperature, economiser outlet temperature and the mean feeder coal flow to mitigate clinker formation problems in coal-fired boilers.

\section{Conclusion}

The outcome of this research illustrate various problem statements and the devised solution respectively. . The objectives of this study was achieve by determining the best ANN models to represent clinker formation conditions inside the boiler. Also, the input-output relationship of the ANN model has also been identified. The methodology must be studied to enhance and develop the system in order to provide further improvements.

This study focused on studying the output patterns of the model and coming up with the best ANN model to benefit the power plant station. Firstly, the main input and output parameters were identified. This allows the progress for trial and error to determine the best RMSE ANN model. It turns out that the $2 \mathrm{HL}$ RNN has the lowest RMSE value out of all the other 6 types of Neural Network.

Moving on to the outcome analysis, It seems that the 2HL RNN model can be utilised to best represent the prediction model for clinker formation. However, each output has their own specific type of ANN that best suit its representation. The $1 \mathrm{HL} \mathrm{CNN}$ is most suited for the change in temperature for mean final superheater outlet temperature. For the change in temperature for mean HT reheater outlet temperature, the $2 \mathrm{HL}$ RNN best describe the output. In addition, the $2 \mathrm{HL}$ RNN is able to predict the mean outlet flue gas temperature accurately.

The tornado diagram has shown the importance of the input parameters in relation to the output parameters. It is important to understand the relationship between them so that the input parameters can be adjust accordingly to control the phenomena inside the boiler. The most influential input parameters includes the mean burner tilt position, economiser inlet temperature, mean economiser outlet temperature and the mean feeder coal flow. It also turns out that the mean air/PF mixture strength is the least influential input parameter for the three outputs, and therefore can be exempted from future studies and ANN modelling of the clinker formation in power plant boilers.

Thus by using the 2HL RNN model, an intelligent prediction system can be built to monitor the clinker formation conditions in the boiler. The model will be able to help the power generation sector as it can achieve a more sustainable business.

\section{Recommendations for Future Works}

It is highly recommended that further study is carried out on using Fuzzy Logic machine learning to better represent the boiler model.Exemption of the mean air/PF mill strength as input to the model is also recommended as it has little to no effect on the output of the model. Other than that, precise data acquisition on the input and output parameter with larger variable pool can be implemented to create a better and accurate model. A more detailed study on the mechanical and chemical aspect of the clinker formation using CFD is strongly encouraged. 
The authors would like to express gratitude to Power Generation Unit, Institute of Power Engineering, Universiti Tenaga Nasional (UNITEN) and Tenaga Nasional Berhad (TNB) for providing research grant to carry out this research.

\section{References}

1. H.B. Vuthaluru. Remediation of Ash Problems in Pulverised Coal-Fired Boilers. Fue/ 78: 1789-1803 (1999)

2. E. Raask, Mineral Impurities in Coal Combustion Behaviours Problems and Remedial Measures (New York, USA: Hemisphere Publishing ,(1985)

3. Z.H. Ma, F. Iman, P.S. Lu, R. Sears, L.B. Kong, A.S. Rokanuzzaman, D.P. McCollor, S.A. Benson, A Comprehensive Slagging and Fouling Prediction Tool for Coal-Fired Boilers and Its Validation/Application. Fuel Processing Technology 88:1035-1043, 2007)

4. R. Singh and L. Srivastava, Line Flow Contingency Selection and Ranking Using Cascade Neural Network. Neurocomputing 70: 2645-2650, 2007)

5. Satish Kumar. Ravali Cherukun. A Survey on Artificial Intelligence Techniques in Power Station. International Journal of Innovative Research in Science, Engineering and Technology (IJIRSET) 6(1) (2017)

6. Samuel. A.Oluwadare. Gabriel B.Iwasokun. Olatubosun Olabode. O.Olusi. Akintobe E. Akinwonmi. Genetic Algortihm- based Cost Optimization Model for Power Economic Dispatch Problem. British Jorunal of Applied Science \& Technology 15(6) :1-10 (2016)

7. Arun Kumar D R. Murali Mohan B M. Artificial Intelligence in Power Station. International Journal of Engineering and Technical Research (IJETR) 5(1) (2016)

8. E. Teruel, C.Cortes, L.I. Diez, I. Aruazo. Monitoring and Prediction of Fouling in Coal-fired Utility Boilers Using Neural Networks. Chemical Engineering Science 60: 5035-5048, (2005)

9. J. Purbolaksono, J. Ahmad, L.C. Beng, A.Z. Rashid, A. Khinani, A.A. Ali. Failure Analysis On A Primary Superheater Tube of A Power Plant. Engineering Failure Analysis 17: 158-167, (2010)

10. M.M. Rahman, J. Purbolaksono, J. Ahmad. Root Cause Failure of A Division Wall Superheater Tube of A Coal-fired Power Station. Engineering Failure Analysis 17: 1490- 1494, (2010)

11. J. Ahmad, M.M. Rahman, M.H.A. Zulhairi, S. Ramesh, M.A. Hassan, J. Purbolaksono. High Operating Steam Pressure and Localized Overheating of A Primary Superheater Tube. Engineerig Failure Analysis 26:344-348, (2012)

12. B. Pena, E. Teruel, L.I. Diez. Soft-computing Models For Soot-blowing Optimization in Coal-fired Utility Boilers. Applied Soft Computing 11: 16571668, (2011)

13. H.B. Vuthaluru, N. Kotadiya, R. Vuthaluru, D. French. CFD Based Identification of Clinker Formation Regions in Large Scale Utility Boiler. Applied Thermal Engineering 31: 1368-1380, (2011)

14. J.M. Lee, D.W. Kim, J.S. Kim. Characteristics of Cocombustion of Anthracite with Bituminous Coal in
A 200-MWe Circulating Fluidized Bed Boiler. Energy 36: 5703-5709, (2011)

15. S.Goyal and G.K. Goyal. Cascade and Feedforward Backpropagation Artificial Neural Network Models For Prediction of Sensory Quality of Instant Coffee Flavoured Sterilized Drink. Machine Learning and Pattern Recognition 2(6)

16. A. Sriram. P.R. Venkateswaran. Sishaj P. Simon. Prediction of Induced Draft Fan Power Consumption in 500MW Steam Generators using Artificial Neural Network. IEEE. (2017)

17. T.E. Boukelia. O. Arslan. M.S. Mecibah. Potential Assessment of a Parabolic through Solar Thermal Power Plant Considering Hourly Analysis : ANNbased approach. Renewable Energy 105 :324-333 (2016)

18. S.A. El-Temtamy and T.S. Gendy. Economic Evaluation and Sensitivity Analysis of Some Fuel Oil Upgrading Processes. Egyptian Journal of Petroleum 23: 397-407

19. H.B. Vuthaluru and D.H. French. Mineralogical Investigations into Clinker Formation and Variation in Deposit Characteristics with Time in A largescale PC-fired Boiler. Fue/ 150:184-190, (2015)

20. A.Arjunwadkar, P.Basu, B. Acharya. A Review of Some Operation and Maintenance Issues of CFBC Boilers. Applied Thermal Engineering 102:672694, (2016)

21. Victor Henrique Cabral Pinheiro. Roberto Schirru. Genetic Programming Applied To The Identifiication of Accidents of a PWR Nuclear Power Plant. Annals of Nuclear Energy 124 :335-341 (2018)

22. K.L Priddy and P.E Keller. Artificial Neural Network: An Introduction .Bellingham, Washington : SPIE Press (2005)

23. B. Yegnanarayana. Artificial Neural Networks.New Delhi:Pretice-Hall of India. (2006)

24. D. Barh, M.S. Khan, E. Davies. PlantOmics: The Omics of Plant Science.New Delhi, India: Springer India (2015)

25. E.E Khalil. "Performance and Testing of Steam Generators" in Power Plant Design, Montreux 2,CH: Gordon and Breach Science, pp. 125 (1990)

26. A.Saltelli. (2004) Sensitivity Analysis in Practice: $A$ guide to Assessing Scientific Models, Hoboken, $\mathrm{Nj}$ : John Wiley \& Sons

27. R.D. Neufville and S Scholtes. (2011) Flexibility in Engineering Design, Canbridge, MA: M.I.T Press

28. National Industrial Fuel Efficiency Service (Great Britain). (1989), Boiler Operators Handbook, London,UK: Graham \& Trotman 